\title{
Comparison of Mortality and Morbidity in Syrian and Turkish Premature Babies with Patent Ductus Arteriosus
}

\author{
Birol Karabulut1, Ayse Şimşek²
}

${ }^{1}$ Buca Gynecology and Children Diseases Hospital, Clinic of Pediatrics, Division of Neonatology, İzmir, Turkey

${ }^{2}$ Buca Gynecology and Children Diseases Hospital, Clinic of Pediatrics, Division of Pediatric Cardiology, İzmir, Turkey

\begin{abstract}
Background: Having observed that the clinical course of premature infants at the 28th gestational week and earlier followed-up in our department was different between races, we aimed to examine the effect of the genetic structure on patent ductus arteriosus (PDA) regarding morbidity and mortality among Turkish and Syrian babies.

Methods: This single-center, retrospective study was carried out with 43 Turkish newborns (group 1) and 31 Syrian newborns (group 2) with a gestational age of 28 weeks or less who had been followed-up between February 2016 and March 2018 in our department after exclusion of the risk factors that may affect ductus arteriosus, and
\end{abstract}

compared the morbidity and mortality of the study groups.

Results: The diameter of the duct, the left atrium/aortic root ratio, the need for ductus occluding intervention, bronchopulmonary dysplasia, hospital stay and mortality rate were significantly higher in Syrian newborns (group 2).

Conclusion: The higher morbidity and mortality rate of PDA in our Syrian patients may be related to the low socioeconomic level resulting from the war in Syria or the difference in the genetic structure.

Keywords: Ductus arteriosus, race, genetic factors 


\section{Introduction}

Patent ductus arteriosus (PDA) is one of the most common cardiovascular diseases with an incidence of $27 \%$ among newborns at or below $28^{\text {th }}$ gestational weeks. ${ }^{(1)}$ According to the presence and hemodynamic effects of PDA, it may cause a number of morbidities including pulmonary hemorrhage, bronchopulmonary dysplasia (BPD), decrease in cerebral oxygenation and neurodevelopmental maturation disorder, intraventricular hemorrhage (IVH), acute renal failure, nutrition intolerance, necrotizing enterocolitis (NEC), retinopathy of prematurity (ROP), sepsis and longer hospital stay, and even mortality. ${ }^{(2,3)}$

The most important risk factors that cause the ductus arteriosus to remain open are the gestational week and low birth weight. Besides, respiratory distress syndrome, antenatal steroid use, chorioamnionitis, fluid management, sepsis, small for gestational age (SGA) baby, genetic factors and drug use are other risk factors. ${ }^{(4-11)}$

Although the incidence, morbidity and mortality rates of PDA have been reported country by country in previous studies, there are few studies on the genetic factors belonging to different races. As we observed that the clinical course of premature infants at $28^{\text {th }}$ gestational week and earlier followed-up in our department was different between races, we decided to compare Syrian and Turkish premature newborns with PDA in terms of morbidity and mortality, and aimed to explore the effect of genetic structure on the PDA outcome.

\section{Materials and Methods}

This single-center and retrospective study was carried out with 78 Turkish newborns (group 1) and 71 Syrian newborns (group 2) with a gestational age of 28 weeks or less who had been followed-up in our department between February 2016 and March 2018. Seventy-five babies with risk factors, who have been presented in Figure 1, causing the duct to remain patent, were excluded from the study to determine the effect of the race factor.

Transthoracic echocardiography was performed routinely within the first 24-72 hours of life according to the recommendation of the Turkish Neonatology Association for newborns with a gestational age of 28 weeks or less. ${ }^{(12)}$ Echocardiographic examinations were performed using the Vivid S6 Echocardiography System (General Electric's Healthcare, Milwaukee, WI). The ductal inner diameter and left atrial (LA)/aortic root (Ao) ratio were measured by echocardiography. The ductus diameter/body weight ratio of $>1.4 \mathrm{~mm} / \mathrm{kg}$ and LA/Ao ratio of $>1.5$ were considered hemodynamically significant PDA (hsPDA). ${ }^{(12)}$ Peroral treatment with oral acetaminophen was administered at a dose of $15 \mathrm{mg} / \mathrm{kg}$, every 6 hours for three days, or ibuprofen at a dose of 10 $\mathrm{mg} / \mathrm{kg}$ in the $1^{\text {st }}$ day, $5 \mathrm{mg} / \mathrm{kg}$ in the $2^{\text {nd }}$ day, and $5 \mathrm{mg} / \mathrm{kg}$ on the $3^{\text {rd }}$ day orally.

The patients' gestational age, birth weight, gender, ductus diameter, LA/Ao ratio, whether or not the patient had received medical treatment for PDA closure (if so, which drug was administered), and the diagnoses of IVH, NEC, BPD and ROP were noted at discharge or death age. Diagnosis of NEC was established according to the Modified Bell's criteria ${ }^{(13)}$; the diagnosis of IVH was based on the Papile classification ${ }^{(14)}$, the ROP diagnosis was made according to the criteria of the International ROP Classification Committee ${ }^{(15)}$, and BPD was according to oxygen requirement at the $36^{\text {th }}$ postmenstrual week.

\section{Statistical Analysis}

Statistical analyses were performed using the statistical package SPSS for Windows version 17.0 (SPSS Inc., Chicago, Illinois). The paired samples t-test and independent samples t-test were used for continuous variables. The chi-square test was used for categorical variables. Continuous variables are presented as the mean $\pm \mathrm{SD}$, and categorical variables are given as frequencies and percentages. A p value of less than 0.05 was considered statistically significant.

\section{Results}

During the course of our study between February 2016 and March 2018, a total of 43 Turkish (group 1) 


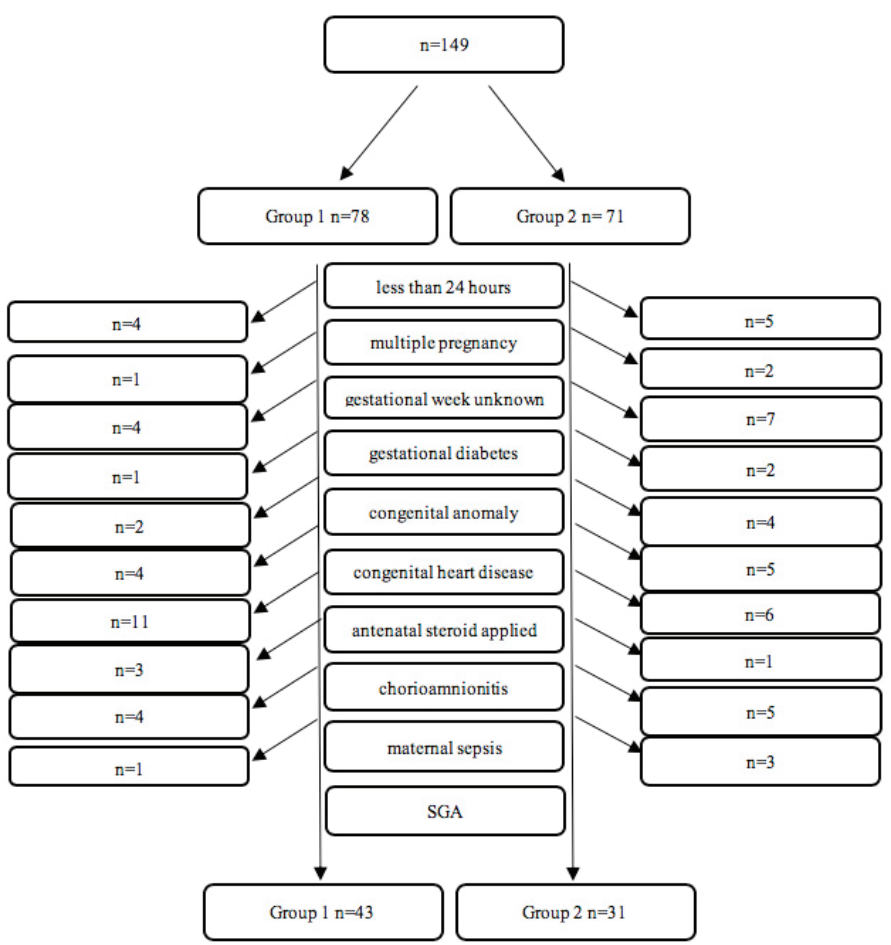

Figure 1. Flowchart of study

SGA: Small for gestational age

and 31 Syrian (group 2) newborns who had been born at 28 weeks of gestation or less were included in the study. The two groups were compared in terms of natal period characteristics (Table 1). There was no difference in gestational age, birth weight, sex, type of delivery and APGAR scores between the study groups ( $p>0.05$, for all; Table 1).

When the echocardiography findings and the treatment results of PDA were compared, we found that the ductus diameter was larger, the LA/Ao ratio was higher, and the requirement for ductus closure treatment was more frequent in Syrian infants ( $<<0.05$, for all; Table 2).

There was no difference between the two groups in terms of surfactant requirement, ventilation support requirement and type of ventilation ( $p>0.05$, for all; Table $3)$.

When the study groups were compared in terms of morbidity and mortality; the frequency of BPD, length of hospital stay and mortality rate of the babies in group 2
Table 1. Comparison of the natal parameters between group 1 and group 2

\begin{tabular}{|c|c|c|c|}
\hline Parameter & Group 1 & Group 2 & p value \\
\hline $\begin{array}{l}\text { Gestational age } \\
\text { (weeks) }\end{array}$ & $26.81 \pm 1.12$ & $26.73 \pm 0.96$ & 0.07 \\
\hline Birth weight (gr) & $969 \pm 287$ & $921 \pm 274$ & 0.23 \\
\hline Sex (male/female) & 24/19 & $18 / 13$ & 0.18 \\
\hline $\begin{array}{l}\text { Mode of delivery } \\
\text { (C/S, VD) }\end{array}$ & $27 / 16$ & $23 / 8$ & 0.63 \\
\hline APGAR 1' & $7.06 \pm 0.66$ & $6.31 \pm 0.89$ & 0.54 \\
\hline APGAR 5' & $8.23 \pm 0.57$ & $6.77 \pm 0.36$ & 0.77 \\
\hline
\end{tabular}

Table 2. Comparison of patent ductus arteriosus parameters between group 1 and group 2

\begin{tabular}{|l|l|l|l|}
\hline Parameter & Group 1 & Group 2 & p value \\
\hline $\begin{array}{l}\text { Postnatal age of } \\
\text { diagnosis }\end{array}$ & $2.3 \pm 1.2$ & $1.4 \pm 0.5$ & 0.01 \\
\hline $\begin{array}{l}\text { Ductal diameter } \\
\text { LA/Ao ratio }\end{array}$ & $1.82 \pm 0.56$ & $2.4 \pm 0.75$ & 0.02 \\
\hline $\begin{array}{l}\text { Closed without } \\
\text { treatment }\end{array}$ & $\begin{array}{l}21 \\
(48.8 \%)\end{array}$ & $8(25.8 \%)$ & 0.01 \\
\hline $\begin{array}{l}\text { Ductal non-surgical } \\
\text { losure }\end{array}$ & $\begin{array}{l}22 \\
(51.2 \%)\end{array}$ & $23(74.2 \%)$ & 0.03 \\
\hline $\begin{array}{l}\text { Ductal surgical } \\
\text { closure }\end{array}$ & 0 & 0 & - \\
\hline
\end{tabular}

LA/Ao: Left atrium to aortic root ratio

were significantly higher than those in group $1(\mathrm{p}<0.05$, for all; Table 4).

According to these results, the mortality and morbidity of the newborns with PDA in group 2 were higher.

\section{Discussion}

One of the most important factors contributing to morbidity and mortality among the newborns is hsPDA. The relation of hsPDA, which is diagnosed echocardiographically, with some morbidities, particularly chronic lung disease, and even mortality, has been investigated in recent years. During the follow-up of very low birth weight newborns admitted to our department in the last three years, we observed that the incidence and severity of PDA, medical treatment requirement for ductus closure, and the morbidity and mortality rates 
Table 3. Comparison of respiratory support between group 1 and group 2

\begin{tabular}{|c|c|c|c|}
\hline Parameter, n (\%) & Group 1 & Group 2 & $p$ value \\
\hline $\begin{array}{l}\text { Received } \\
\text { surfactant }\end{array}$ & 37 (86\%) & $30(96.7 \%)$ & 0.91 \\
\hline HFV & $3(6.9 \%)$ & $3(9.6 \%)$ & 0.47 \\
\hline CMV & $34(79 \%)$ & $27(87 \%)$ & 0.83 \\
\hline nCPAP & $6(13.9 \%)$ & $1(2 \%)$ & 0.52 \\
\hline $\begin{array}{l}\text { Received } \\
\text { dexamethasone }\end{array}$ & $4(9.3 \%)$ & $3(9.6 \%)$ & 0.33 \\
\hline
\end{tabular}

HFV: High frequency ventilation, CMV: Conventional mechanical ventilation, $n C P A P:$ Nasal continuous positive airway pressure

Table 4. Comparison of patent ductus arteriosus outcome between group 1 and group 2

\begin{tabular}{|c|c|c|c|}
\hline Parameter, n (\%) & Group 1 & Group 2 & $p$ value \\
\hline Nosocomial sepsis & $11(25.5 \%)$ & $7(22.5 \%)$ & 0.36 \\
\hline IVH & $8(18.6 \%)$ & $8(25.8 \%)$ & 0.12 \\
\hline NEC & $4(9.3 \%)$ & $4(12.9 \%)$ & 0.73 \\
\hline ROP & $2(4.6 \%)$ & $2(6.4 \%)$ & 0.53 \\
\hline BPD & $7(16.3 \%)$ & $11(35.4 \%)$ & 0.01 \\
\hline $\begin{array}{l}\text { Duration of hospital } \\
\text { stay (days) }\end{array}$ & $67.4 \pm 21.3$ & $79.7 \pm 34.8$ & 0.03 \\
\hline Death & $6(13.9 \%)$ & $9(29 \%)$ & 0.01 \\
\hline
\end{tabular}

were higher in Syrians newborns. Thus, we compared the Turkish and Syrian newborns with a gestational age of 28 weeks or less in terms of morbidity and mortality. There was no difference in gestational age, birth weight, sex, type of delivery and the APGAR score between the two groups, whereas we found that PDA was more severe, and the incidence of BPD, the length of hospital stay and the mortality rate were higher in Syrian infants. The PDA became symptomatic earlier, and the ductus diameter and the LA/Ao ratio were higher in group 2 . Previous studies have demonstrated the relationship between the ductus diameter and morbidity and mortality. Schena et al. reported that the amount and duration of the ductal shunt were associated with the length of hospital stay, the development of BPD and mortality. ${ }^{(16)}$ Sehgal et al. developed a ductal staging system using functional echocardiography on 372 preterm infants born before the $32^{\text {nd }}$ gestational week and found that BPD and mortality increased as the stage increased. ${ }^{(17)}$ Sellmer et al. reported that as the PDA diameter increased, the frequency of IVH, BPD and mortality also increased. ${ }^{(18)}$ Although these studies do not establish a causal relationship between PDA and mortality, the most commonly accepted view suggests that the morbidity and mortality increase as the amount of shunt increases. In our study, the presence and severity of PDA and the amount of shunt were higher together with a longer hospital stay and higher BPD and mortality rates in the Syrian babies. Although the factors that may affect the presence and severity of PDA (gestational age, birth weight, antenatal steroid use, chorioamnionitis, early sepsis, SGA), were similar between the two groups, the most probable explanation for the higher severity of PDA and the medical treatment requirement for ductus closure in group 2 was the difference in the genetic structure.

Although many studies have been conducted on the diagnostic methods and treatment options of PDA, there is a limited number of previous researches investigating the genetic basis of PDA. Human and animal studies on this subject focus on the genetic loci that may result in increased susceptibility to PDA. Treszl et al. showed that AT1R CC genotype of PDA developed at a lower rate than the AA and AC genotype. ${ }^{(19)}$ In a study by Petrova et al. comparing the newborns from black, white, Hispanic and other races with a gestational age of 32 weeks and below, they showed that the mortality of black newborns with the same gestational age and birth weight was lower than that of others. ${ }^{(20)} \mathrm{Li}$ et al. showed that PRDM6 mutations caused larger PDAs. ${ }^{(21)}$ Zidan et al. and Zhu et al. found that the C677T allele of the MTHFR gene was associated with atrial septal defect and PDA. ${ }^{(22,23)}$ In another study by Dagle et al., genetic mutations of transcription factor activating protein-2, tumor necrosis factor receptor-associated factor 1 and prostacyclin synthase were found to be associated with PDA. ${ }^{(24)}$ Waleh et al. showed that the expression of SLCO2A1 and NOS3 decreased the success of indomethacin and ibuprofen in ductus closure by increasing the prostaglandin synthesis 
in the Caucasian race. ${ }^{(25)}$ Waleh et al. demonstrated that three calcium and potassium-channel genes (CACNA1G/ alpha1G, CACNB2/CaL-beta2, and KCNA2/Kv1.2), were associated with prostaglandin inhibition and emphasized the consideration of these genes in the development of future medical treatment strategies for PDA closure. ${ }^{(26)}$ In another study, Mangones et al. investigated the prevalence of congenital heart diseases (CHD) and showed that PDA was most commonly seen in non-hispanic whites. ${ }^{(27)}$ In their study with 200 patients with CHD, Qiao et al. found that MEF2C mutation was associated with PDA. ${ }^{(28)}$ These previous studies suggest that the incidence and severity of PDA differ from race to race due to some kinds of mutations and differences in genetic structures, and the genetic structure even determines the success rate of the drugs used in the medical treatment for closure.

In our study, we observed that the ductus was usually wider in Syrian babies, and it is known that the larger ductus results in hemodynamically more severe shunt and increased morbidity and mortality. The reason for the ducts being wider in Syrian infants may be due to the different genetic structures mentioned above in these infants. Therefore, it is reasonable that the genetic coding of premature Syrian babies can lead to larger PDAs and consequently lead to higher mortality rates.

\section{Conclusions}

Although the risk factors were similar in both groups, we found that the presence and severity of PDA and consequently the morbidity and mortality related to PDA were higher among Syrian patients in our study. We think that this difference may be due to the low socioeconomic level resulting from the war in Syria or the difference in genetic structure. We believe that an important risk factor for PDA is the genetic structure of the individual and that a decrease in the uncertainty of genetic structure with future studies will lead to changes in the diagnosis and treatment of PDA and increase the success rate and survival.

Disclosure and conflicts of interest: The authors declare no conflict of interest.

\section{References}

1. Weinberg JG, Evans FJ, Burns KM, Pearson GD, Kaltman JR. Surgical ligation of patent ductus arteriosus in premature infants: trends and practice variation. Cardiol Young 2015;26:1107-14.

2. Mirea L, Sankaran K, Seshia M, et al. Treatment of patent ductus arteriosus and neonatal mortality/morbidities: Adjustment for treatment selection bias. J Pediatr 2012;161:689-94

3. Sehgal A, McNamara PJ. The ductus arteriosus: A refined approach. Semin Perinatol 2012;36:105-13.

4. Clyman RI, Ballard PL, Sniderman S, et al. Prenatal administration of betamethasone for prevention of patient ductus arteriosus. J Pediatr 1981;98:123-6.

5. Park HW, Choi YS, Kim KS, Kim SN. Chorioamnionitis and patent ductus arteriosus: A systematic review and meta-analysis. PLoS One 2015;16;10:e0138114.

6. Kim ES, Kim EK, Choi CW, et al. Intrauterine inflammation as a risk factor for persistent ductus arteriosus patency after cyclooxygenase inhibition in extremely low birth weight infants. J Pediatr 2010;157:745-50.

7. Rakza T, Magnenant E, Klosowski S, Tourneux P, Bachiri A, Storme L. Early hemodynamic consequences of patent ductus arteriosus in preterm infants with intrauterine growth restriction. J Pediatr 2007;151:424-8.

8. Shelton EL, Ector G, Galindo CL, et al. Transcriptional profiling reveals ductus arteriosus specific genes that regulate vascular tone. Physiol Genomics 2014;46:457-66.

9. Bhandari V, Zhou G, Bizzarro MJ, et al. Genetic contribution to patent ductus arteriosus in the premature newborn. Pediatrics 2009;123:669-73.

10. Reese J, Veldman A, Shah L, Vucovich M, Cotton RB. Inadvertent relaxation of the ductus arteriosus by pharmacologic agents that are commonly used in the neonatal period. Semin Perinatol 2010;34:222-30.

11. Capozzi G, Santoro G. Patent ductus arteriosus: patho-physiology, hemodynamic effects and clinical complications. J Matern Fetal Neonatal Med 2011;24(Suppl 1):15-6.

12. Turkish Neonatology Association's Approach to Patent ductus arteriosus in a premature baby 2016 .

13. Walsh MC, Kliegman RM. Necrotizing enterocolitis: treatment based on staging criteria. Pediatr Clin North Am 1986;33:179-201.

14. Papile LA, Burstein J, Burstein R, Koffler H. Incidence and evolution of subependymal and intraventricular hemorrhage: a study of infants with birth weights less than 1,500gm. J Pediatr 1978;92:529-34.

15. International Committee for the Classification of Retinopathy of Prematurity. The international classification of retinopathy of prematurity revisited. Arch Ophthalmol 2005;123:991-9.

16. Schena F, Francescato G, Cappelleri A, et al. Association between hemodynamically significant patent ductus arteriosus and bronchopulmonary dysplasia. J Pediatr 2015;166:1488-92.

17. Sehgal A, Paul E, Menahem S. Functional echocardiography in staging for ductal disease severity: role in predicting outcomes. Eur J Pediatr 2013;172:179-84. 
18. Sellmer A, Bjerre JV, Schmidt MR, et al. Morbidity and mortality in preterm neonates with patent ductus arteriosus on day 3. Arch Dis Child Fetal Neonatal Ed 2013;98:505-10.

19. Treszl A, Szabo M, Dunai G, et al. Angiotensin II type 1 receptor A1166C polymorphism and prophylactic indomethacin treatment induced ductus arteriosus closure in very low birth weight neonates. Pediatr Res 2003;54:753-5.

20. Petrova A, Mehta R, Anwar M, Hiatt M, Hegyi T. Impact of Race and Ethnicity on the Outcome of Preterm Infants Below 32 Weeks Gestation. J Perinatol 2003;23:404-8.

21. Li N, Subrahmanyan L, Smith E, et al. Mutations in the Histone Modifier PRDM6 Are Associated with Isolated Nonsyndromic Patent Ductus Arteriosus. Am J Hum Genet 2016;98:1082-91.

22. Zidan H, Rezk NA, Mohammed D. MTHFR C677T and A1298C gene polymorphisms and their relation to homocysteine level in Egyptian children with congenital heart diseases. Gene 2013;529:119-24.

23. Zhu WL, Li Y, Yan L, Dao J, Li S. Maternal and offspring MTHFR gene C677T polymorphism as predictors of congenital atrial septal defect and patent ductus arteriosus. Mol Hum Reprod 2006;12:51-4.
24. Dagle JM, Lepp NT, Cooper ME, et al. Determination of genetic predisposition to patent ductus arteriosus in preterm infants. Pediatrics 2009;123:1116-23.

25. Waleh N, Barrette AM, Dagle JM, et al. Effects of Advancing Gestation and Non-Caucasian Race on Ductus Arteriosus Gene Expression. J Pediatr 2015;167:1033-41.

26. Waleh N, Hodrick R, Jhaveri N, et al. Patterns of Gene Expression in the Ductus Arteriosus Are Related to Environmental and Genetic Risk Factors for Persistent Ductus Patency. Pediatr Res 2010;68:292-7.

27. Mangones T, Manhas A, Visintainer P, Hunter-Grant C, Brumberg HL. Prevalence of congenital cardiovascular malformations varies by race and ethnicity. Int J Cardiol 2010;143:317-22.

28. Qiao XH, Wang F, Zhang XL, et al. MEF2C loss-of-function mutation contributes to congenital heart defects. Int J Med Sci 2017;14:1143-53. 